\title{
A SURVEY OF HUMAN RABIES IN IRAN; 2000-2006
}

\author{
Ahmad Fayaz, Firouzeh Farahtaj ${ }^{*}$, Naser Eslami, Nader Howaizi, Peyvand Biglari \\ Alireza Janani Susan Simani \\ Center For Research and Reference on Rubies, Pasteur Institute, Tehran, Iran
}

\begin{abstract}
Rabies is a fatal disease, which is the most important viral zoonosis from a global perspective. Human rabies encephalitis still remains a serious public health problem in developing countries such as Iran, which had only 45 human rabies cases during 2000-2006. In this regard, epidemiological studies on bite injuries, animal and local situation would provide a useful and accessible source of epidemiological information. This data could be used effectively to enhance rabies surveillance in human populations, trends of the disease incidence and improve the allocation of medical resources and assess the effectiveness of rabies control measures implemented against rabies. In this study, we present and discuss human rabies cases who suffered severe face, head, neck, arm and legs injuries when attacked by a rabid animal and also suggest a hypothesis concerning possible causes of death from rabies 23 brain samples of rabid individuals from different parts of Iran have been diagnosed by FAT and MNT methods. Kerman province had the highest rate of human rabies in Iran and dog bites is the most common source of infection, although in mountainous area, dog and wolf have been considered the reservoir of the disease. The data also suggest the route of entering of rabies virus and the degree of postexposure treatment a patient receives could predict the outcome of the disease and fate of patients.
\end{abstract}

Keywords: • Human rabies $\bullet$ Post-exposure Treatment $\bullet$ Vaccine

\section{Introduction}

$\mathrm{R}$ abies is a deadly viral disease affecting the central nervous system [1],[2] and is most often transmitted through the bites, licks or scratch of rabid animals[3]. Rabies virus binds to nicotinic acetylcholine receptors at the motor end plates. The virus moves centripetally along peripheral nerves within axons by retrograde fast axonal transport at a rate of approximately 50 to $100 \mathrm{~mm}$ daily. Neurons in the spinal cord become infected, followed by rapid intra-axonal spread of the virus throughout the central nervous system along neuroanatomic pathway.

Subsequently, there is centrifugal spread of the virus along nerves to multiple organs in animals and humans, including the salivary glands in rabies vectors [4].

*Corresponding Author: Dr. Firouzeh Farahtaj: WHO-Collaborating Centre for Reference \& Research on Rabies, Pasteur Institute of Iran, 13164 Tehran, Iran.

Tel: +982166403496 Fax: +982166480777

E-mail: farahtaj@pasteur.ac.ir
Human rabies encephalitis is rarely seen in the industrialized countries of the temperate zone [5] but remains a serious public health problem in many developing countries. At last 60000 human deaths and 10 millions post-exposure treatments are reported each year in the world [6]. There are many inconsistencies in the reported incidence of human rabies. Several explanations for underreporting have been proposed.

Patients with clinical rabies may stay at home or seek treatment from local healers, most cases do not receive laboratory confirmation, causes of death may be recorded locally but are not transmitted to the central authorities, a small proportion of deaths attributable to rabies may not be recognized as such by medical staff [7].

This study investigates the value of details about the contacts, the animals and local epidemiologic situations after a potential rabies exposure, to decide whether to initiate post-exposure prophylaxis. It is also important to improve effectively rabies diagnosis and surveillance in human communities. 


\section{Material \& Methods}

Post-mortem brain samples of 23 rabid humans from different parts of the country, were sent to WHO-Collaborating Centre for Reference \& Research on Rabies, Pasteur Institute of Iran, during 2000 to 2006 were tested in vitro for rabies. Rabies was diagnosed on the basis of the clinical picture and confirmed by direct Fluorescent Antibody Technique(FAT), using antinucleocapsid antibody conjugate, followed by Mouse Inoculation Test(MNT) according to WHO recommended protocols [7]. Briefly, brain smears were fixed by cold acetone, dried, incubated with antineucleocapsid antibody for an hour, washed with PBS and distilled water subsequently, and observed under UV microscope.

\section{Results}

23 brain samples of 45 human rabies cases from different provinces of Iran during 2000 to 2006 were assessed by FAT and MNT methods and for the rest of cases [22], were diagnosed clinically
(Table 1). The highest rate of human rabies in Iran was detected in Kerman province.

The highest rate of human rabies in Iran was detected in Kerman province (Table 1).

The highest rate of deaths due to rabies is in the age group of less than 20 years of age (Table 2).

Table 2 Age-group distribution of human rabies death

In different provinces of Iran

\begin{tabular}{|l|lc|}
\hline $\begin{array}{l}\text { Age-group } \\
\text { (Years) }\end{array}$ & \multicolumn{2}{|l|}{$\begin{array}{l}\text { Human Rabies Cases } \\
\text { No./Percent }\end{array}$} \\
\hline $1-20$ & 12 & $52.2 \%$ \\
\hline $21-40$ & 7 & $30.4 \%$ \\
\hline $41-60$ & 2 & $8.7 \%$ \\
\hline $61-80$ & 2 & $8.7 \%$ \\
\hline
\end{tabular}

Out of 23 rabid individuals, 14 were bitten by dogs, 3 by wolves, 2 by foxes, one by jackal, one by wild cat, and one had been exposed to rabid sheep and one is undetermined.

In 11 of injured cases the wounds could be found in their heads (face, ears, neck, temple and frontal

Table 1 No. of human rabies cases from different provinces of Iran During 2000-20006

\begin{tabular}{|c|c|c|c|c|c|c|c|c|}
\hline $\begin{array}{ll}\text { Provinces } & \text { Year } \\
\end{array}$ & 2000 & 2001 & 2002 & 2003 & 2004 & 2005 & 2006 & Total \\
\hline Qum & 1 & - & - & - & - & - & - & 1 \\
\hline Kermanshah & 1 & - & 1 & - & - & - & - & 2 \\
\hline Markazi & 1 & - & - & - & - & - & - & 1 \\
\hline Kerman & 1 & 1 & 1 & 4 & 1 & 1 & 2 & 11 \\
\hline Isfahan & 2 & - & - & - & - & - & - & 2 \\
\hline Hormozgan & 1 & - & - & 1 & 1 & - & 1 & 4 \\
\hline Semnan & 1 & - & - & - & - & - & - & 1 \\
\hline Kohgiloyeh\&Boyerahmad & 1 & - & - & - & - & - & - & 1 \\
\hline Elam & - & 1 & - & - & 1 & - & - & 2 \\
\hline Hamedan & - & 1 & 1 & - & - & - & - & 2 \\
\hline Khuzestan & - & - & 1 & 1 & - & - & - & 2 \\
\hline Khorasan & - & - & 1 & - & - & - & - & 1 \\
\hline Kurdestan & - & - & - & 1 & 1 & 1 & 1 & 4 \\
\hline Lorestan & - & - & - & 2 & - & 2 & - & 4 \\
\hline West Azarbaijan & - & - & - & 1 & - & - & - & 1 \\
\hline Fars & - & - & - & - & 1 & - & 1 & 2 \\
\hline Yazd & - & - & - & - & - & - & 1 & 1 \\
\hline Tehran & - & - & - & - & - & - & 2 & 2 \\
\hline Mazandaran & - & - & - & - & & - & - & 1 \\
\hline Total & 9 & 3 & 6 & 10 & 5 & 4 & 8 & 45 \\
\hline
\end{tabular}


areas), two had wounds in their legs and feet, 9 in their hands and fingers and one is not clear. Of 23 bitten individuals, 14 have not received any postexposure treatment, 5 had delayed or incomplete post-exposure treatment, and finally 4 received post-exposure treatment, which one of them had sutured her face wounds.

The mean incubation period of the disease for each year has been shown in Table 3 .

Table 3 Mean incubation periods of rabies disease During 2000-2006

\begin{tabular}{|c|c|}
\hline Year & $\begin{array}{c}\text { Mean Incubation Period } \\
\text { (Days) }\end{array}$ \\
\hline 2000 & 58.4 \\
\hline 2001 & 42 \\
\hline 2002 & 17.5 \\
\hline 2003 & 54.5 \\
\hline 2004 & 40 \\
\hline 2005 & 28.5 \\
\hline 2006 & 36 \\
\hline
\end{tabular}

The longest mean incubation period is 58.4 days which could be found in the year 2000. Also, the patients who had bitten by dogs and cats had approximately a mean incubation period of 32.8 days but in victims who have bitten by wild animals such as foxes, wolves and jackals is approximately 62.8 days (Table 4 ).

Table 4 Mean incubation periods of rabies disease Caused by different animals bites

\begin{tabular}{|c|c|}
\hline Animals & $\begin{array}{c}\text { Mean Incubation } \\
\text { Period } \\
\text { (Days) }\end{array}$ \\
\hline Dogs \& Cats & 32.8 \\
\hline $\begin{array}{c}\text { Foxes, Jackals and } \\
\text { Wolves }\end{array}$ & 62.8 \\
\hline
\end{tabular}

\section{Discussion \& Recommendations}

Rabies is an acute encephalomyelitis caused by rabies virus. Dogs, foxes, jackals, and wolves presumed as the vector species in Iran [8] which is consistent with the canine rabies-endemic regions with large stray-dog populations that the overwhel-ming majority (95-98\%) of cases of human rabies occurs following dog bites. Control of disease in these settings often is hampered by cultural, social and economic realities (Buddhist and Hindu ethics restrain culling of the canine population, India and Thailand have prohibited the killing of stray dogs by municipalities) [9] but fortunately in Iran, dog-mediated rabies had been controlled by destroying the stray dogs in Tehran with a joint project of Pasteur Institute of Iran, municipal of Tehran and other organizations in 1977[10]. In central and eastern Europe and north America, most human rabies cases are associated with contacts to wild carnivores and bats whose role has been consider-ably increasing in recent years [9].

As indicated in this study, most of rabid individuals had bitten by dog, and the rest by wolf and sheep. Kerman province could be considered as the most infected area of Human Rabies during 2000 to 2006 since it had at least one human rabies case in every year. According to data published by S.A. Nadin-davise et al, the Iranian rabies strains are most closely related to isolates from dogs in Nepal and northern India [8].

The human rabies cases in western provinces of Iran (mountainous area) generally caused by dog and wolf whilst in other parts of the country, are due to dogs and rarely sheep.

In addition to natural way of host entering, broken skin caused by a bite or scratch, the rabies virus could penetrate through intact mucous membrane as well as inhalation of an aerosol, and can be transplanted in an infected corneal graft. Vertical transmission from mother to fetus and from lactating mother to suckling young has been described in nonhuman mammals and is alleged to occur in humans [11].

One of the principal factors influencing the outcome of a bite from a rabid animal is the location of the bite on the body. Bites on the hand, face and neck for example carry a much higher risk than bites on a foot or legs. In this study most of the injured individuals had bites on their hands and heads.

Rabies disease typically has an incubation period approximately 1 to 3 months and rarely, more than 1 year [4]. As shown in, the mean incubation periods in this study (Tables 3 and 4) are consistent with the data presented by Alan Jackson [4], except for the year 2002, which is less than 1 month (17.5days) and is compatible with the data of Henry Wild in Thailand [12]. In this regard, the incubation period of the disease in patients who had bitten by domestic animals (cats, dogs...) is shorter than by wild canid (Jackals, foxes and wolves). The long incubation period in rabies is likely the result of a delay in movement of the virus at the site of bite [4]. 
Most of the 55000 deaths from rabies reported annually around the world occur in Asia and Africa, and most of the victims are children (30$50 \%$ ) under 15 years of age [13]. According to table 2, most of the deaths from rabies are belonged to children and young adults.

Human rabies is entering preventable through appropriate post-exposure treatment or vaccination of reservoir hosts [6] although therapy of rabies with antiviral agents, including an open trial with intravenous Ribavirin or Interferon alpha (combin- ed intravenous and intrathecal administration), was unsuccessful [4] but the use of Vidarabin and Interferon alpha has been tried for patients with a late stage of disease. Experimentally, only a monoclonal antibody has proved effectively.

Among this, Ketamin which is a dissociative anesthetic agent and a noncompetitive antagonist of the N-methyl-D-aspartate (NMDA) receptor, has sedative and analgesic properties and rapidly crosses the blood-brain barrier. At high concentrations (1-2 $\mathrm{mM})$, Ketamine has been demonstrated

Table 5 WHO-Recommendations for post-exposure Treatment Type of contact, exposure and recommended post-exposure prophylaxis

\begin{tabular}{|c|l|c|c|}
\hline Category & $\begin{array}{l}\text { Type of contact with a } \\
\text { suspect or confirmed rabid } \\
\text { domestic or wild animal, or } \\
\text { unavailable for testing (a) }\end{array}$ & $\begin{array}{c}\text { Type of } \\
\text { exposure }\end{array}$ & Recommended post-exposure prophylaxis \\
\hline I & $\begin{array}{l}\text { Touching or feeding of } \\
\text { animals }\end{array}$ & None & None, if reliable case history is available \\
\hline II & $\begin{array}{l}\text { Licks on intact skin } \\
\text { Minor scratches or } \\
\text { abrasions without bleeding } \\
\text { (b) }\end{array}$ & Minor & $\begin{array}{l}\text { Administer vaccine immediately } \\
\text { treatment if animal remains healthy } \\
\text { throughout an observation period of 10 daysc or } \\
\text { if animal is proven to be negative for rabies by a } \\
\text { reliable laboratory using appropriate diagnostic } \\
\text { techniques }\end{array}$ \\
\hline III & $\begin{array}{l}\text { Single or multiple } \\
\text { transdermal bites or } \\
\text { scratches, licks on broken } \\
\text { skin(c) } \\
\text { Contamination of mucous } \\
\text { membrance with saliva } \\
\text { (i.e.licks) } \\
\text { Exposure to bats (d) }\end{array}$ & Severe & $\begin{array}{l}\text { Administer rabies immunoglobulin and vaccine } \\
\text { immediately. Stop treatment is animal remains } \\
\text { healthy throughout an observation period of 10 } \\
\text { rabies by animal is found to be negative for } \\
\text { diagnostic techniques }\end{array}$ \\
\hline
\end{tabular}

a) Exposure to rodents, rabbits and hares seldom, if ever, requires specific anti-rabies post-exposure prophylaxis.

b) If an apparently healthy dog or cat in or from a low-risk area is placed under observation, the situation may warrant delaying initiation of treatment.

c) This observation period applies only to dogs and cats. Except in the case of threatened or endangered species, other domestic and wild animals suspected as rabid should be humanely killed and their tissues examined for the presence of rabies antigen using appropriate laboratory techniques.

d) Post-exposure prophylaxis should be considered when contact between a human and a bat has occurred unless the exposed person can rule out a bite or scratch, or exposure to a mucous membrane. 
to inhibit the in vitro replication of rabies virus by inhibiting rabies virus genome transcription [14], otherwise it has not been recommended or confirmed by WHO-Expert co-mmittee on rabies and needs more investigations.

WHO-Guidelines for post-exposure treatment have been shown in table 5, according to this table, persons who are bitten or scratched by any animal should wash wounds thoroughly and seek immediate medical attention [15] and followed the WHO recommendations for post-exposure treatments.

Most human rabies cases occur because of one or more of the following reasons:

1) No post-exposure treatment of any kind is used; as indicated in the results, 6 of injured individuals had not received any treatment.

2) Rabies immune globulin is unaffordable.

3) Treatment is significantly delayed or inappropriate. In this study, 4 bitten cases had incomplete or delayed treatment.

4) Acute illness, malnutrition or other underlying conditions compromise appropriate immune responses.

It should be considered that the wounds must not be sutured as much as may possible and the wound should first be infiltrated with passive rabies immunization products and suturing delayed for several hours [16], due to this reason one of the dead victims in this study had sutured her wounds in her face.

Documented failure of human rabies post-exposure treatment are uncommon [17], but there have been previous reports of failures of post-exposure treatment of rabies in which tissue culture-derived vaccines and immune globulins had been used. Each of these reported failures resulted in death, and in each case there had been delays in treatment and flows or omissions with regard to use of current World Health Organization (WHO) treatment guidelines [12] and surveillance for such events is, in many cases, inadequate [17]. There has been a failure of human post-exposure treatment in this study probably due to insufficient/neglited infiltration of Human Rabies Immunoglobulin (HRIG) around the wounds [16], among this, it should be considered that infiltration of HRIG around the wounds in some parts of body such as extremities or fingers would be very difficult.

This study demonstrates that data on bite injuries provide a useful and accessible source of epidemiological information that could be used effectively to enhance rabies surveillance in human and animal populations, detect trends in disease incidence, improve the allocation of medical and veterinary resources and assess the impact of rabies control measures [6].

\section{References}

1 http://www.charmeck.org/departments/health+departmen t $/$ rabies $+28^{\text {th }}+$ case $+7-14-03$.ht.

2 http://horrycounty.org/newsrelease/nr-072502b.html.

3 http://www.cdc.gov/ncidod/dvrd/rabies/introduction/intr o.htm.

4 Alan C Jackson, 2003; Rabies, In Current Treatment Options in Infectious Diseases, Current Inc. 5:35-40.

5 Chokri B., Sami Ban Haj A., Beya Iman B.,Habib Kh., El Akrem H., Koussey D.; 2003; Estimating Human Rabies Mortality in the United Republic of Tanzania from Dog Bite Injuries, Vaccine 22:177-184.

6 Cleaveland S., Fevre E.M., Kaare M., Coleman P.G., 2002; Bulletin of the world Health Organization 80(4):304-310.

7 Dean D.J., Ableseth M.K., Atanasiu P.; 1996; The Fluorescent Antibody Test. In Laboratory Techniques in Rabies, $4^{\text {th }}$ edn., ., Kaplan M.,Koprowski H., World Health Organization, Geneva pp:88-95.

8 Nadin-Davis S.A., Simani S.,Armstrong J., Fayaz A and Wandeler A.I; 2003; Molecular and antigenic characterization of rabies viruses from Iran identifies variants with distinct epidemiological origins. Epidemi-ol. Infect. 131:777-790.

$9 \mathrm{http} / / / \mathrm{www} . \mathrm{who}$. int/vaccine research/diseases/zoonotic/e n/index $5 . h$ tm

10 Fayaz A, 2000, Rabies, In Epidemiology \& Control of Common Diseases in Iran, Eshtiagh publication, pp:552557.

11 Warrell D A, and Warrell M.J; 1988; Human Rabies and its Prevention: An Overview. Reviews of Infectious Disease.10:S726-S731.

12 Wild H, Sirikawin S, Sabaharoen A, Kingnate D, Tantawichien T, Harischandra P A L, Chaiyabutr N, D.G.H. de Silva, Fernando L, Liyanaga J.B., and Sitprija V; 1996; Failure of Post-exposure Treatment of Rabies in Children, Clinical Infectious Diseases 22:228-32.

$13 \mathrm{http} / / / \mathrm{www}$. who.int/rabies/en.

14 Jackson A. et al. 2003; Management of Rabies in Humans, CID, $13: 60-63$.

15 Rabies, Human-USA:MMW Reports; 2000; MMWR 49:1111-1115.

16 WHO Expert Consultation on Rabies, 2005 Geneva, Switzerland, First Report, WHO Technical Report Series 931, World Health Organization, pp:67-68.

17 Hanlon C.A., Niezgoda M., Morril P.A., Rupprecht C.E.; 2001; The incurab; e wound revisited: Progress in human rabies prevention, Vaccine 19:2273-2279 